\title{
PENERAPAN TEKNOLOGI TEPAT GUNA PENGHANCUR SAMPAH ALAT SUNTIK DI UPTD PUSKESMAS SEMBERBERAS MUNCAR BANYUWANGI
}

\author{
Dian Ridlo Pamuji ${ }^{\# 1}$, Dedy Hidayat Kusuma ${ }^{* 2}$,Galang Sandy Prayogo ${ }^{\# 3}$ \\ ${ }^{\#}$ Jurusan Teknik Mesin, Politeknik Negeri Banyuwangi \\ Jl. Raya Jember Km.13 Labanasem Kabat Banyuwangi \\ ${ }^{1}$ ridlodianepoliwangi.ac.id \\ ${ }^{3}$ gasandylangelive.com \\ *Jurusan Teknik Informatikan, Politeknik Negeri Banyuwangi \\ Jl. Raya Jember Km.13 Labanasem Kabat Banyuwangi \\ ${ }^{2}$ dedyepoliwangi.ac.id
}

\begin{abstract}
Abstrak
Limbah medis sangat penting untuk dikelola secara benar, hal ini mengingat limbah medis termasuk kedalam kategori limbah berbahaya dan beracun. Salah satu limbah medis yang berbahaya adalah alat suntik atau disposable syringe. Menurut Peraturan Menteri Kesehatan Republik Indonesia Nomor 86 Tahun 2013, alat suntik merupakan alat kesehatan sekali pakai. Penggunaan yang berulang antar pasien dari alat suntik dapat menularkan penyakit. Kegiatan di rumah sakit maupun di Pusat Kesehatan Masyarakat atau PUSKESMAS akan menghasilkan banyak limbah medis salah satunya disposable syringe atau alat suntik. Limbah tersebut harus segera dihancurkan agar tidak membahayakan manusia di sekitarnya. Puskesmas Sumberberas merupakan salah satu unit pelayanan kesehatan masyarakat di Kecamatan Muncar yang menghasilkan sampah medis seperti disposable syringe atau alat suntik kurang lebih $10 \mathrm{Kg}$ per bulan yang harus di olah atau dihancurkan. Saat ini Puskesmas Sumberberas belum memiliki penghancur alat suntik sendiri untuk mengolah sampah medis khususnya alat suntik sehingga harus bekerjasama dengan pihak eksternal yaitu PT. Pria Mojokerto. Dalam merancang mesin melibatkan mitra dan mahasiswa Program Studi Teknik Mesin. Tahap awal kegiatan pengabdian ini adalah melakukan survey untuk mengidentifikasi permasalahan yang dihadapi oleh mitra dan melakukan studi literatur untuk mendapatkan solusi atas permasalahan mitra. Setelah solusi permasalahan mitra didapatkan, langkah selanjutnya melakukan perancangan mesin yang dibutuhkan yaitu mesin penghancur alat suntik. Mesin penghancur alat suntik ini diharapkan dapat membantu mitra dalam mengolah limbah medis khususnya limbah alat suntik.
\end{abstract}

Kata Kunci — alat suntik, limbah medis, mesin penghancur alat suntik.

\section{PENDAHULUAN}

Limbah medis sangat penting untuk dikelola secara benar, hal ini mengingat limbah medis termasuk kedalam kategori limbah berbahaya dan beracun. Salah satu limbah medis yang berbahaya adalah alat suntik atau disposable syringe. Dalam dunia medis sering kita jumpai berbagai alat suntik dengan berbagai ukuran. Alat suntik digunakan untuk mentransfer obat-obatan dalam bentuk cairan kedalam tubuh manusia ataupun hewan yang hendak melakukan perawatan dan pengobatan.

Menurut Peraturan Menteri Kesehatan Republik Indonesia Nomor 86 Tahun 2013, alat suntik merupakan alat kesehatan sekali pakai. Penggunaan yang berulang antar pasien dari alat suntik dapat menularkan penyakit, misalnya HIV/AIDS. Jika jarum pernah digunakan oleh orang yang mengidap HIV/AIDS, jarum yang pernah digunakan tersebut digunakan lagi pada orang yang sehat, maka orang tersebut akan terkena infeksi HIV. Kegiatan di rumah sakit maupun di Pusat Kesehatan Masyarakat atau PUSKESMAS akan menghasilkan banyak limbah medis salah satunya disposable syringe atau alat suntik. Limbah tersebut harus segera dihancurkan agar tidak membahayakan manusia di sekitarnya. Berdasarkan Peraturan Menteri Kesehatan ( Permenkes ) No. 28 Tahun 2011, salah satu persyaratan izin mendirikan dan menyelenggarakan klinik harus melampirkan dokumen Upaya Pengelolaan Lingkungan (UKL) dan Upaya Pemantauan Lingkungan (UPL).

Puskesmas Sumberberas merupakan salah satu unit pelayanan kesehatan masyarakat di Kecamatan Muncar yang melayani rawat inap. Rata-rata Setiap bulan Puskesmas Sumberberas menghasilkan sampah medis seperti disposable syringe atau alat suntik kurang lebih $10 \mathrm{Kg}$. Bahkan pada bulanbulan tertentu seperti saat imunisasi, Puskesmas Sumberberas menghasilkan $70 \mathrm{Kg}$ sampah alat suntik yang harus dihancurkan. Saat ini Puskesmas Sumberberas belum memiliki penghancur alat suntik sendiri untuk mengolah sampah medis khususnya alat suntik sehingga harus bekerjasama dengan pihak eksternal yaitu PT. Pria Mojokerto dengan biaya Rp. $25.000 / \mathrm{Kg}$. 


\section{TARGET DAN LUARAN}

Target pengabdian pada masyarakat adalah Unit Pelayanan Teknis Daerah (UPTD) Puskesmas Sumberberas Kecamatan Muncar Banyuwangi. Berdasarkan permasalahan yang dihadapi oleh mitra, maka solusi yang ditawarkan adalah penerapan teknologi tepat guna untuk menghancurkan sampah alat suntik yang dihasilkan oleh puskesmas Sumberberas. Dengan adanya mesin penghancur alat suntik ini, diharapakan bisa membantu Puskesmas Sumberberas dalam menghancurkan sampah medis seperti alat suntik.

\section{METODE PELAKSANAAN}

Prosedur kerja pelaksanaan kegiatan pengabdian masyarakat yang akan dilaksanakan mengikuti diagram alir seperti ditunjukkan pada Gambar 1 .

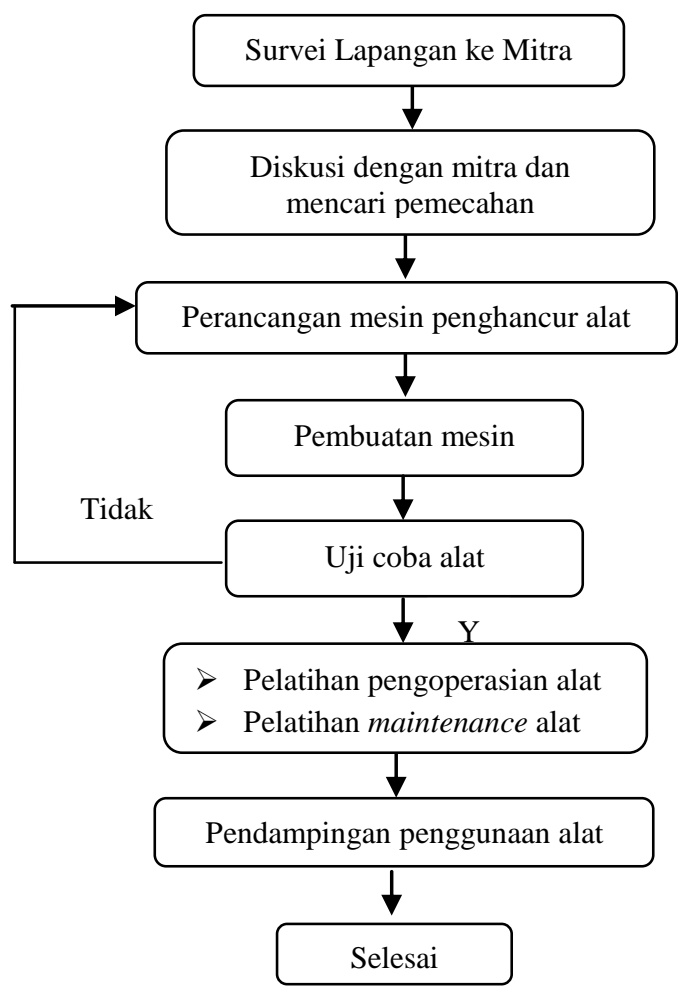

Gambar 1. Diagram alir pelaksanaan pengabdian

1. Survey Lapangan ke Mitra

Survey lapangan bertujuan untuk mengidentifikasi permasalahan yang dihadapi oleh mitra. Berdasarkan survey yang telah dilakukan Puskesmas Sumberberas Kecamatan Muncar Kabupaten Banyuwangi belum memiliki alat penghancur sampah alat suntik dan harus mengeluarkan biaya ekstra untuk mengolah sampah alat suntik dengan bekerjasama dengan pihak eksternal.

2. Diskusi Dengan Mitra dan Mencari Pemecahan Masalah
Diskusi dengan mitra dilakukan dengan tujuan untuk mencari solusi atas permasalahan yang dihadapi oleh mitra terkait dengan sampah alat suntik. Berdasarkan hasil diskusi, didapatkan bahwa Puskesmas Sumberberas membutuhkan mesin yang dapat digunakan untuk menghancurkan sampah medis berupa alat suntik. Solusi yang ditawarkan pada program pengabdian masyarakat ini adalah dengan membuatkan mesin penghancur sampah alat suntik sehingga dapat membantu Puskesmas Sumberberas untuk menghancurkan sampah alat suntik. Selain itu dengan adanya mesin penghancur alat suntik ini, dapat mengurangi biaya pengeluaran untuk mengolah sampah alat suntik.

3. Perancangan mesin

Sebelum mesin penghancur alat suntik dibuat, terlebih dahulu dilakukan perancangan komponen-komponen yang telah ditentukan berdasarkan beban-beban dan faktor-faktor lainnya yang terjadi pada mesin penghancur alat suntik.

4. Pembuatan mesin

Mesin penghancur sampah alat suntik ini proses pembuatannya dilakukan di workshop pemesinan dan pengelasan Program Studi Teknik Mesin Politeknik Negeri Banyuwangi.

5. Uji coba mesin

Setelah mesin dibuat, dan sebelum diserahterimakan ke mitra, terlebih dahulu dilakukan uji coba mesin.

6. Pelatihan Pengoperasian Mesin

Setelah mesin penghancur sampah alat suntik di uji coba, langkah selanjutnya adalah memberikan pelatihan pengoperasian alat dan perwatan mesin ke mitra.

\section{IV.HASIL DAN PEMBAHASAN}

Berdasarkan permasalahan yang dihadapi oleh mitra, maka diperlukan mesin penghancur sampah medis berupa alat suntik yang mudah penggunaannya sehingga dapat membantu mitra dalam mengolah limbah medis yang berupa alat suntik. Adapun tahapan pelaksanaan kegiatan pengabdian masyarakat ini adalah sebagai berikut:

\section{A. Proses Pembuatan Alat}

Proses pembuatan mesin penghancur alat suntik diawali dengan menentukan design mesin yang mudah pengoperasiaannya. Langkah selanjutnya, dari design yang telah ditetapkan kemudian dilakukan perancangan terhadap komponen-komponen yang telah ditentukan berdasarkan beban-beban dan faktor-faktor lainnya yang terjadi pada mesin penghancur alat suntik agar mesin tersebut aman digunakan dan memiliki massa penggunaan yang lama. Pada tahap perancangan ini 
juga meliputi pembuatan gambar kerja yang nantinya sebagai pedoman pada saat pembuatan Mesin. Komponen mesin penghancur alat suntik berupa pisau penghancur dapat dilihat pada Gambar 2. Setelah semua komponen mesin penghancur alat suntik dibuat, langkah selanjutnya adalah proses perakitan komponen-komponen mesin penghancur alat suntik. Mesin penghancur alat suntik yang sudah dirakit dapat dilihat pada Gambar 3 dan Gambar 4.

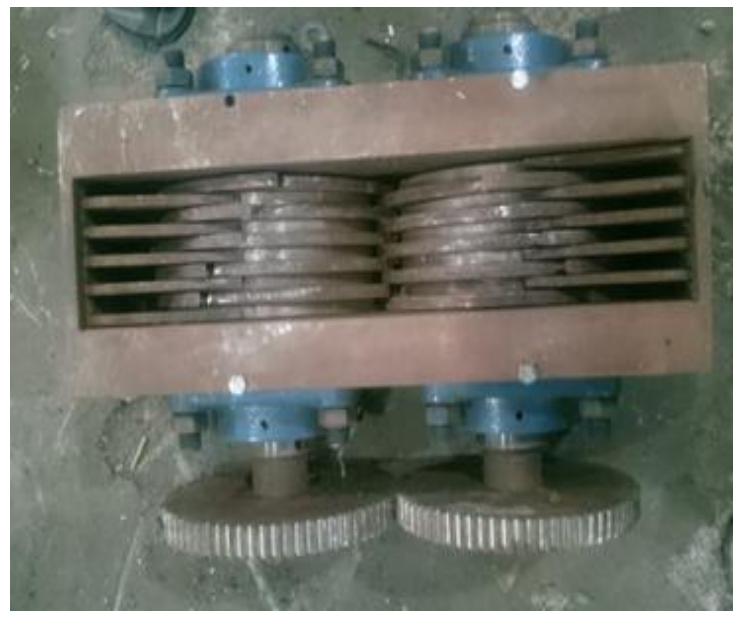

Gambar 2. Pisau penghancur alat suntik

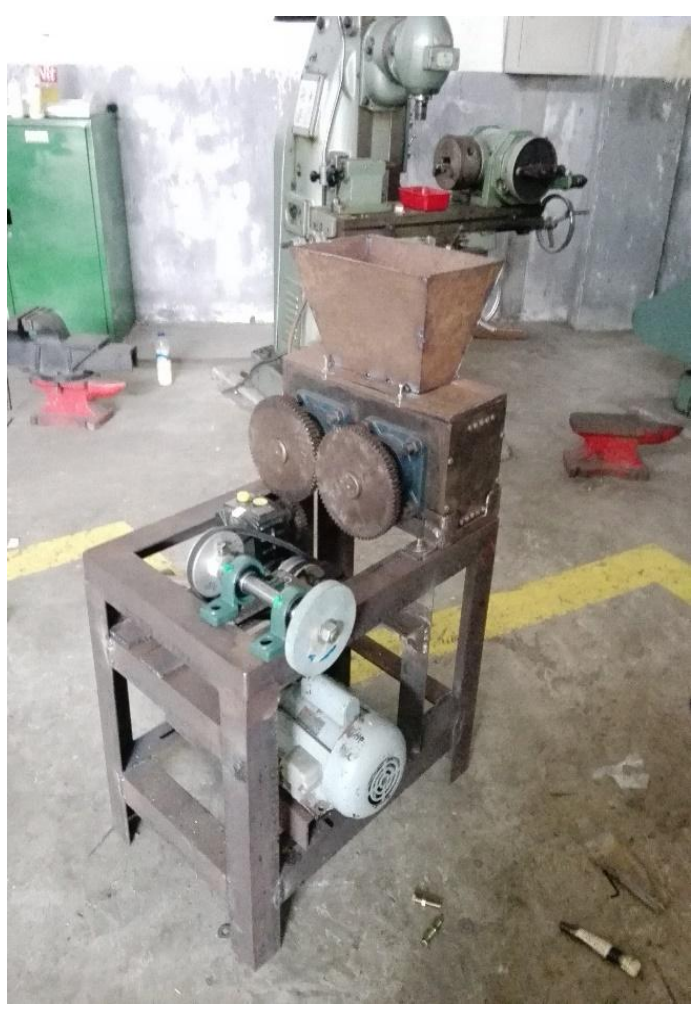

Gambar 3. Mesin penghancur alat suntik sebelum dilakukan pengecatan

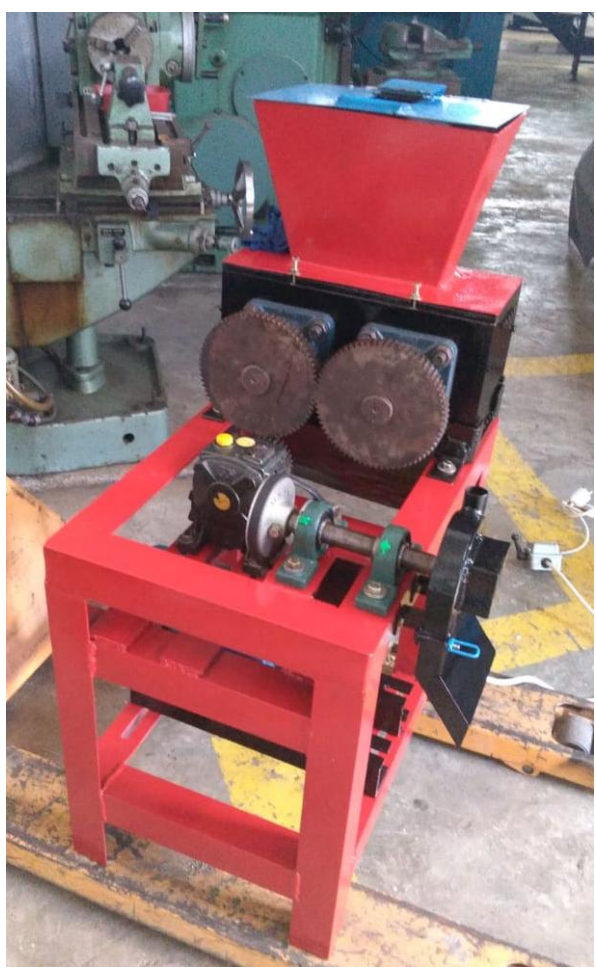

Gambar 4. Mesin penghancur alat suntik

\section{B. Uji Coba Mesin Penghancur Alat Suntik}

Setelah Mesin penghancur alat suntik jadi, sebelum dilakukan transfer teknologi kepada mitra, dilakukan uji coba terhadap Mesin yang sudah dibuat. Hal ini bertujuan untuk memastikan bahwa Mesin penghancur alat berfungsi dengan optimal. Proses uji coba mesin penghancur alat sunti seperti ditunjukkan pada Gambar 5a dan Gambar 5b.

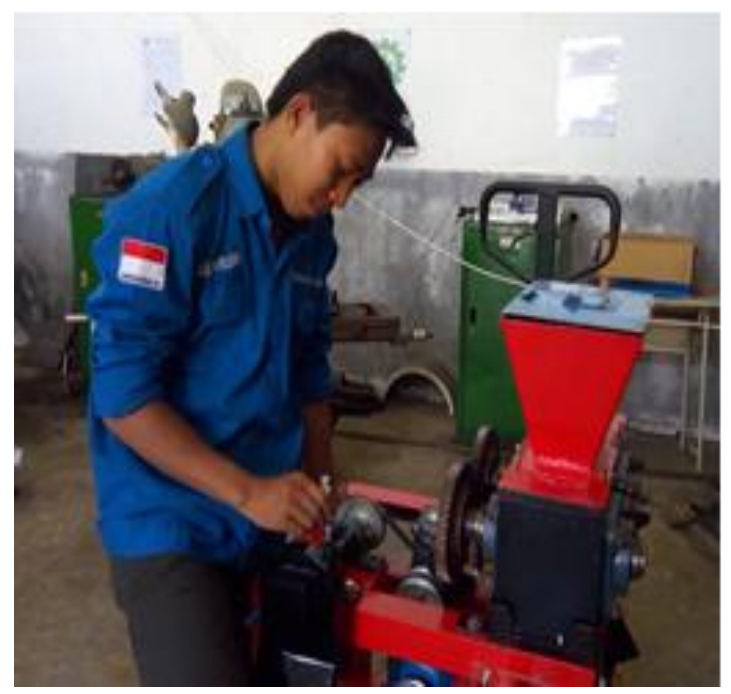

Gambar 5a. Uji coba mesin penghancur alat suntik 


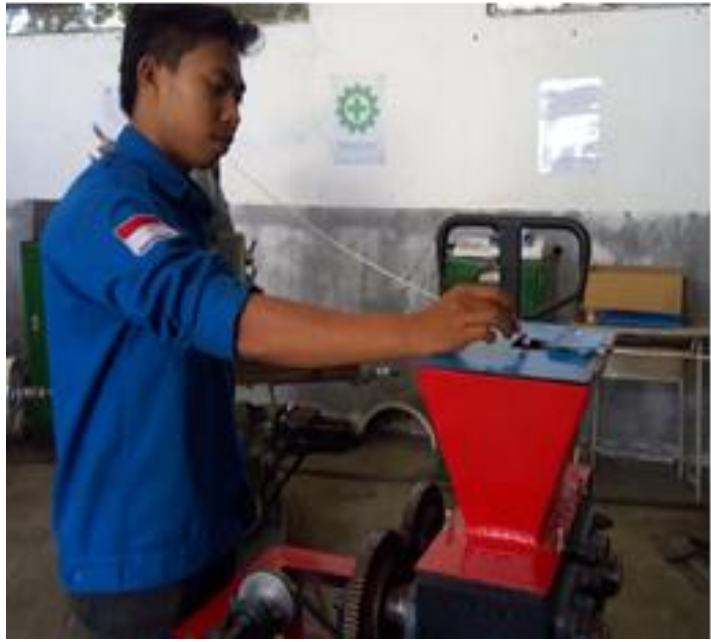

Gambar 5b. Uji coba mesin penghancur alat suntik

\section{Penyerahan dan Pelatihan Penggunaan Mesin Kepada Mitra}

Setelah uji coba mesin penghancur alat suntikan dilakukan dan hasilnya sesuai dengan spesifikasi, tahap selanjutnya adalah peneyerahan mesin kepada mitra di UPTD puskesmas Sumberberas kecamatan Muncar. Pada saat serah terima mesin, juga dilakukan pelatihan singkat penggunaan mesin beserta proses perawatannya seperti ditunjukkan pada Gambar 6a dan 6b. Dengan adanya kegiatan ini, diharapkan mitra mampu mengoperasikan mesin penghancur alat suntik sesuai prosedur. Selain mampu mengoperasikan mesin penghancur suntikan, diharapkan mitra dapat melakukan perawatan terhadap mesin, agar penggunaan mesin bisa optimal dan dengan perawatan yang baik dapat meningkatkan umur pemakaian mesin penghancur alat suntik. Selain itu, dengan kegiatan ini diharapkan mitra mampu melaksanakan perbaikan jika ada kerusakan pada mesin

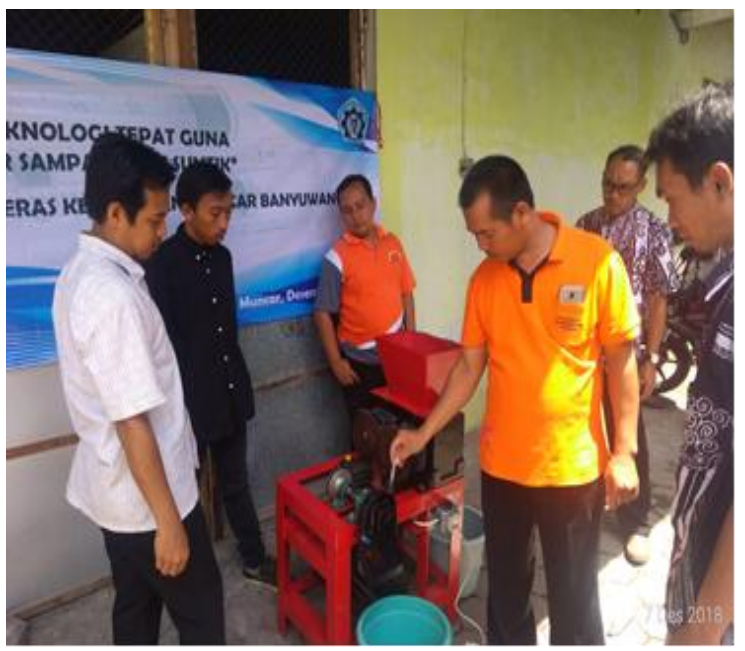

Gambar 6a. Pelatihan pengoperasian dan perawatan mesin

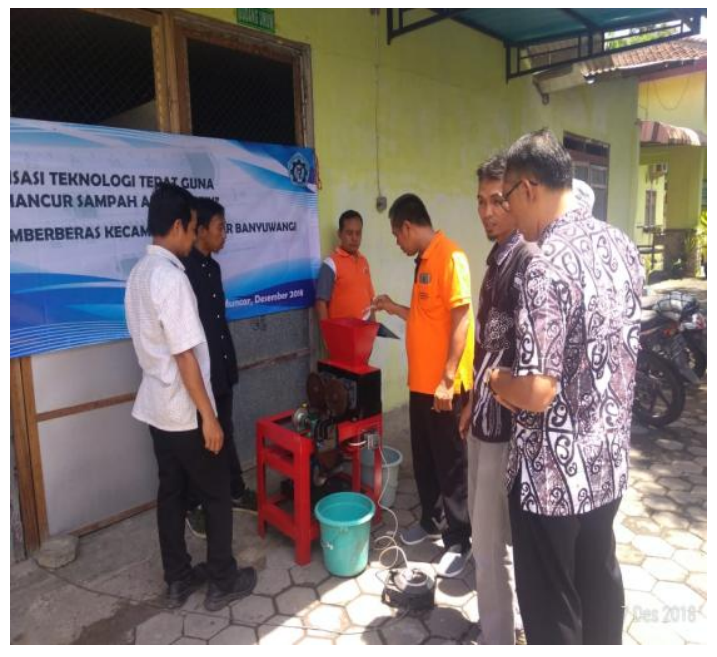

Gambar 6b. Pelatihan pengoperasian dan perawatan mesin

\section{KESIMPULAN}

Berdasarkan hasil kegiatan pengabdian kepada masyarakat yang telah dilaksanakan, maka dapat disimpulkan bahwa:

1. Mitra sangat antusias pada saat kegiatan serah terima mesin dan pelatihan pengoperasian mesin dan perawatan mesin.

2. Dengan adanya mesin penghancur alat suntik hasil dari program pengabdian kepada masyarakat ini dapat membantu mitra dalam menghancurkan limbah medis yang berupa alat suntik.

\section{UCAPAN TERIMA KASIH}

Penulis mengucapkan terima kasih kepada Politeknik Negeri Banyuwangi Sesuai dengan Kontrak Penelitian Nomor: 3596.03/PL36/PM/2018 yang telah memberi dukungan finansial terhadap kegiatan pengabdian kepada masyarakat ini.

\section{DAFTAR PUSTAKA}

[1] Peraturan Menteri Kesehatan Republik Indonesia Nomor 86 Tahun 2013 Tentang Peta Jalan Pengembangan Industri Alat Kesehatan.

[2] Batan, L.I., 2012. Desain Produk. Edisi Pertama. Guna Widya, Surabaya.

[3] Sularso, 1997. Dasar - dasar Perencanaan dan Pemeliharaan Elemen Mesin. Pradnya Paramita, Jakarta.

[4] Verlag, W.G., 1966. Westerman Tables. Wiley Eastern Limited. 